\title{
Wall mannoproteins in cells from colonial phenotypic variants of Candida albicans
}

\author{
Jose P. Martinez, ${ }^{1}$ M. Luisa Gil, ${ }^{1}$ Manuel Casanova, ${ }^{1}$ Jose L. Lopez-Ribot, ${ }^{1}$ \\ Juan Garcia De Lomas ${ }^{2}$ and Rafael SentandReU ${ }^{1 *}$ \\ ${ }^{1}$ Departamento de Microbiología, Facultad de Farmacia, and ${ }^{2}$ Facultad de Medicina, Universitat de València, \\ 46010-València, Spain
}

(Received 23 July 1990; accepted 31 July 1990)

\begin{abstract}
Candida albicans ATCC 26555 switched at high frequency $\left(10^{-1}\right.$ to $\left.10^{-3}\right)$ between several phenotypes identified by colony morphology on a defined mineral amino-acid-containing agar medium supplemented with arginine and zinc (LAZ medium). When cells taken from colonies exhibiting distinct morphologies were plated directly onto LAZ agar, spontaneous conversion to all the variant phenotypes occurred at combined frequencies of $2 \cdot 1 \times 10^{-1}$ to $9.5 \times 10^{-3}$. However, when cells taken from the different colonial phenotypes were plated directly onto an undefined medium (yeast extract/peptone/dextrose; YPD medium), or first incubated in liquid YPD medium and then cloned on YPD agar, all colonies observed exhibited the same phenotype (smooth-white). When cells from the smooth-white colonies were plated as clones on LAZ agar, the original switch phenotype reappeared. These results suggest that environmental conditions such as the growth medium (and possibly the temperature) influence switching by suppressing phenotype expression, but have no effect on genotype. The variant colony morphologies also appeared to be associated with differences in the relative proportions of yeast and mycelial cells. Zymolyase digests of wall preparations obtained from cells belonging to different colonial phenotypes were analysed by SDSPAGE. After blotting to nitrocellulose paper, the mannoproteins were stained with Concanavalin A, with a polyclonal antiserum enriched in antibodies against mycelium-specific wall components, and with a monoclonal antibody raised against a high-molecular-mass mannoprotein band $(260 \mathrm{kDa})$ specific to the walls of mycelial cells. The results suggest that phenotypic switching might be associated with changes in the degree of glycosylation in high-molecular-mass mannoproteins, or in the way these mannoproteins are bound to other cell wall components.
\end{abstract}

\section{Introduction}

The pathogenic character of the dimorphic fungus Candida albicans is thought to be associated with its capacity to grow by production of filamentous forms, as adhesion and penetration of the host cells seem to correlate with this morphology. However, this property alone seems to be insufficient to explain the ability of Candida to (i) infect different animal tissues, (ii) invade distinct immunocompromised hosts, (iii) resist the action of antifungal drugs, and (iv) evade the host immune system (Bodey \& Fainstein, 1985; Chandler, 1985; Odds,

Abbreviations: ConA, concanavalin A; W, wrinkled; SW, smoothwhite; ST, star; P, smooth-white-petite; HM, heavy-myceliated; R, ring; F, fuzzy; FR, flat-ring; SR stippled-ring; HW, hyper-wrinkled; ISWW, intermediate smooth-white-wrinkled.
1988; Rogers \& Balish, 1980; Soll et al., 1987; TapperJones et al., 1981).

It has been reported that most strains of $C$. albicans, and some strains of $C$. tropicalis, switch at a high frequency, both in vivo and in vitro, between different phenotypes, distinguishable by colony morphology on agar (Pomés et al., 1987; Slutsky et al., 1985, 1987; Soll et al., 1987, 1988). At least three distinct switching systems (the 3153A strain switching system, the WO-1 strain transition system, and the smooth-white-heavy-myceliated transition), which are strain-specific and give rise to a limited number of colony phenotypes, have been described in C. albicans (Slutsky et al., 1985, 1987; Soll et $a l .$, 1987). It has been suggested that switching may modulate the pathogenic character of $C$. albicans by conferring on the fungal cells the plasticity to avoid the host immune system and to develop resistance to 
antifungal drugs (Slutsky et al., 1985). Thus, not only can more than one strain colonize the same individual in some cases (Odds, 1987), but also different phenotypes of a single strain may be found at the same site of infection (Odds, 1987; Soll et al., 1987). In addition, it has recently been reported that a single $C$. albicans strain, which was responsible for successive episodes of recurrent vaginitis, switched colony phenotypes between episodes (Soll et al., 1989). Significant differences have been reported in the adhesion characteristics as well as cell surface properties (i.e. ultrastructure and antigenicity) between the socalled 'white' and 'opaque' cell phenotypes in the whiteopaque transition (Anderson et al., 1990; Kennedy et al., 1988), which is one of the three distinct switching systems (the WO-1 strain) described in C. albicans (Slutsky et al., 1987). These observations are of great interest, since adherence of fungal cells to the host tissues seems to play a transient but essential role in colonization.

Wall mannoproteins are the main antigenic components of the $C$. albicans surface (Casanova et al., 1989; Chaffin et al., 1988; Poulain et al., 1985; Sundstrom et $a l ., 1988$ ), and are also implicated in the attachment of $C$. albicans to epithelial cells and to inert surfaces (Douglas, 1987). Consequently, in the present study we have (i) examined the switching capabilities of $C$. albicans ATCC 26555, a common laboratory strain, under different growth conditions, and (ii) monitored the mannoprotein antigens present in the cell wall of the switch phenotypes. The results of this study suggest that phenotypic switching may be accompanied by changes in the pattern of cell-wall-bound antigenic mannoproteins.

\section{Methods}

Organism and maintenance of stock cultures. Stock cultures of $C$. albicans ATCC 26555 were maintained by subculturing every 2-3 weeks on $1.5 \%(\mathrm{w} / \mathrm{v})$ Bacto-Agar slopes of Sabouraud dextrose medium.

Colony plating for analysis of phenotypic switching. For initial plating, cells were removed from a stock culture grown for $24-48 \mathrm{~h}$ at $28^{\circ} \mathrm{C}$ and diluted into double-distilled water at a concentration of approximately $5 \times 10^{3}$ colony-forming units (c.f.u) $\mathrm{ml}^{-1}$, and $0 \cdot 2 \mathrm{ml}$ of this suspension were spread on $2 \%(\mathrm{w} / \mathrm{v})$ Bacto-Agar containing the nutrient components of the medium of Lee et al. (1975) supplemented with $70 \mu \mathrm{g}$ arginine $\mathrm{ml}^{-1}$ and $0.1 \mu \mathrm{M}$ zinc sulphate (LAZ medium; Bedell \& Soll, 1979). Plates were then incubated at $28^{\circ} \mathrm{C}$ for at least $5 \mathrm{~d}$ prior to assessment of colony phenotypes. Each plate contained 100-150 colonies. To determine the switching frequencies of subsequent colonies, and the stability of the different variant colonial phenotypes on different growth media, cells were taken from individual clonal colonies of age 5-7 d, suspended in water, and plated (approx. 200 per plate) either on solid [ $2 \%(\mathrm{w} / \mathrm{v})$ Bacto-Agar] LAZ medium or YPD medium [ $1 \%(\mathrm{w} / \mathrm{v})$ Bacto-Yeast extract, $2 \%(\mathrm{w} / \mathrm{v})$ Bacto-Peptone, $2 \%$ (w/v) dextrose]. The plates were incubated for $5-7 \mathrm{~d}$ at $28^{\circ} \mathrm{C}$ (the protocol followed is described in Table 1). To assess the effect on phenotypic switching of both preincubation in different nutrient media and the incubation temperature, cells removed from selected colonial phenotypes were resuspended into $125 \mathrm{ml}$ Erlenmeyer flasks containing either $25 \mathrm{ml} \mathrm{LAZ}$ medium or $25 \mathrm{ml} \mathrm{YPD}$ medium, and incubated with shaking ( 200 r.p.m.) at $28^{\circ} \mathrm{C}$ for $10-12$ h. Cells from these cultures were suspended in double-distilled water, counted, and plated (approx. 200 cells per plate) on LAZ and/or YPD agar. These plates were then incubated for $5-7 \mathrm{~d}$ at $28^{\circ} \mathrm{C}$ or $37^{\circ} \mathrm{C}$ before examination of colony morphology. The experimental protocols followed in this case are summarized in Tables 2 and 3.

Cell wall preparation. Colonies exhibiting specific morphologies were removed from the surface of the plates, and resuspended independently into chilled $1 \mathrm{mM}$-phenylmethylsulphonyl fluoride (PMSF) in $0.01 \mathrm{M}$ Tris/ $\mathrm{HCl}$ buffer, $\mathrm{pH} 7 \cdot 4$ (buffer $\mathrm{A}$ ). Cells were washed three times with buffer $A$ by centrifugation $(3000 \mathrm{~g}$ for $10-15 \mathrm{~min})$, and broken by vortexing with glass beads $(0.45-0.5 \mathrm{~mm}$ in diameter; $5 \mathrm{mg}$ beads per $\mathrm{mg}$ wet weight of cells). Cell walls were sedimented $(1200 \mathrm{~g}, 10 \mathrm{~min})$ from the cell-free homogenates, and purified by several washes with buffer $A$ as previously described (Casanova et al., 1989). Isolated walls were freeze-dried, and stored at $-20^{\circ} \mathrm{C}$ until further use.

Solubilization of wall antigens by enzymic digestion. Mannoproteins were solubilized from purified walls by treatment with Zymolyase $20 \mathrm{~T}$ (a $\beta$-glucanase complex; $10 \mu \mathrm{g}$ of enzyme complex per $100-150 \mu \mathrm{g}$ of purified freeze-dried cell walls, in $1 \mathrm{~mm}$-sodium azide and $1 \mathrm{mM}-\mathrm{PMSF}$ in $0.01 \mathrm{M}$-Tris $/ \mathrm{HCl}$ buffer, $\mathrm{pH} 7.4$, at $28^{\circ} \mathrm{C}$ for $2 \mathrm{~h}$ (Casanova et al., 1989). After treatment, the wall residue was removed by centrifugation $(1200 \mathrm{~g}, 15 \mathrm{~min})$, and the solubilized material was concentrated by freeze-drying. The total sugar and protein content in the lyophilized material was determined by the method of Dubois et al. (1956) and by the Lowry method, respectively.

$P A G E$ and Western blot techniques. Mannoproteins solubilized after enzymic digestion of the walls were separated by SDS-PAGE, performed basically as described by Laemmli (1970) with the modifications as previously reported (Casanova et al., 1989). Electrophoretic transfer (Western blot) to nitrocellulose paper (Bio-Rad) was performed as described by Burnette (1981) except that the transfer buffer used contained $0.025 \mathrm{M}$-Tris $/ 0.192 \mathrm{M}$-glycine ( $\mathrm{pH} 8.3$ ), and $20 \%$ $(\mathrm{v} / \mathrm{v})$ methanol, and the electrophoretic transfer was carried out at $6-$ $8 \mathrm{~V} \mathrm{~cm}^{-1}$ for $15-17 \mathrm{~h}$ at $4{ }^{\circ} \mathrm{C}$ in Trans-Blot cell (Bio-Rad) using an LKB 2197 power supply. Immunochemical detection of proteins on blots was done by the method described in the Bio-Rad Immun-Blot (GARHRP) assay kit, based on the procedure of Burnette (1981) and Towbin et al. (1979). A polyclonal rabbit serum enriched in antibodies against the overall mannoprotein composition of purified mycelial walls (mPAb), and a mouse monoclonal antibody (mAb 4C12) raised against a mannoprotein band with an average apparent molecular mass of $260 \mathrm{kDa}$, specific for the cell wall of the mycelial morphology of $C$. albicans ATCC 26555, were prepared as previously reported (Casanova et al., 1989) and used as antibody probes. Antibodies were used at a final concentration of $1: 500$ (for pAb) or $1: 3000$ (for $\mathrm{mAb}$ ) in $0.01 \mathrm{M}$ Tris/ $\mathrm{HCl}$ buffer, $\mathrm{pH} \cdot 7 \cdot 4$, containing $3 \%(\mathrm{w} / \mathrm{v})$ bovine serum albumin as blocking agent, $0.9 \% \mathrm{NaCl}$ and $0.05 \%$ Tween 20 . Diluted $(1: 2000)$ peroxidase-labelled goat anti-rabbit, or goat anti-mouse IgG (Bio-Rad) were used as indicator antibodies with 4-chloro-1-naphthol as the chromogenic reagent. Concanavalin A (ConA) staining of nitrocellulose blots was done according to Hawkes (1982) with the modifications of Millette \& Scott (1984).

Chemicals. Gel electrophoresis and blotting reagents were from BioRad. Zymolyase 20T was from Miles Laboratories. SDS molecular mass markers were from Sigma and Pharmacia. Culture media compounds were purchased from Difco. All other chemicals used were purchased from Sigma. 


\section{Results}

Frequency of colony phenotypes after plating of cells of the original strain

When cells of a stock culture of a standard strain of $C$. albicans (ATCC 26555; this strain had been maintained in our laboratory for over five years by repeated subculturing on slopes of Sabouraud-dextrose medium) were plated as clones on plates of LAZ medium, variant colony morphologies appeared spontaneously at frequencies from $4.6 \times 10^{-1}$ to $8.4 \times 10^{-3}$ (Tables 1 and 2). Since the colony morphologies were (Fig. 1), in most cases, closely similar to those of the colonial phenotypes described by Slutsky et al. (1985) in C. albicans 3153A, we have used, where possible, the terminology proposed by these authors to describe our colony variants. Of the total number of primary colonies examined after the initial plating (Table 1), $2139(64.6 \%)$ were smooth-white (SW; Fig $1 b), 1126(34.04 \%)$ were wrinkled (W; Fig. $1 a), 28$ $(0.84 \%)$ were ring (R; Fig. $1 e)$, and $14(0.42 \%)$ were star (ST; Fig. 1c). Different figures were obtained in another plating on LAZ medium, when the variety of switching phenotypes detected was greater (Table 2). Thus, from the total number of colonies scored, $1147(40.6 \%)$ were smooth-white, 387 (13.7\%) were stippled-ring (SR; Fig. $1 \mathrm{~h}), 352(12.5 \%)$ were star, $286(10 \cdot 1 \%)$ were wrinkled, $256(9.0 \%)$ were flat-ring (FR; Fig. $1 \mathrm{~g}$ ) [this colonial variant was somewhat different from the colony morphologies mentioned by Slutsky et al. (1985), so we coined the

Table 1. Proportion of different colony phenotypes obtained after sequential clonal plating of C. albicans ATCC 26555 on LAZ or YPD media

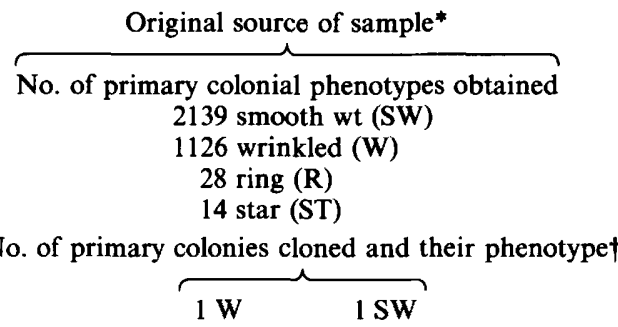

No. of secondary colonial phenotypes appearing on LAZ agar

\begin{tabular}{|c|c|}
\hline $1992 \mathrm{~W}$ & $1658 \mathrm{SW}$ \\
\hline $\begin{array}{l}15 \mathrm{SW} \\
15 \mathrm{ST}\end{array}$ & $16 \mathrm{~W}$ \\
\hline
\end{tabular}

No. of secondary colonies cloned and their phenotype $\dagger$

$\overbrace{1 \mathrm{~W}}^{1 \mathrm{SW}}$

No. of tertiary colonial phenotypes appearing and predominant phenotype obtained after plating of cells from the secondary $W$ or SW colonies on LAZ or YPD agar

$\overbrace{\substack{1643 \mathrm{~W} \\ 15 \mathrm{SW} \\ 14 \mathrm{ST}}}^{\text {LAZ }} \overbrace{1760 \mathrm{SW}}^{\text {YPD }} \overbrace{\substack{2153 \mathrm{SW} \\ 33 \mathrm{~W}}}^{\text {LAZ }} \overbrace{1568 \mathrm{SW}}^{\text {YPD }}$

No. of tertiary colonies cloned and their phenotype $\dagger$

$\overbrace{1 \mathrm{~W} \quad 1 \mathrm{SW}}^{1 \mathrm{SW} \quad 1 \mathrm{SW}}$

No. of quaternary colonial phenotypes appearing and predominant phenotype obtained after plating of cells from the tertiary $W$ or distinct SW colonies on LAZ or YPD agar

\begin{tabular}{|c|c|c|c|c|c|c|c|}
\hline$\underbrace{\mathrm{LAZ}}$ & YPD & $\overbrace{}^{\mathrm{LAZ}}$ & $\underbrace{\text { YPD }}$ & $\overbrace{}^{\mathrm{LAZ}}$ & $\overbrace{}^{\text {YPD }}$ & $\overbrace{\text { LAZ }}^{\text {LA }}$ & YPD \\
\hline $\begin{array}{c}1647 \mathrm{~W} \\
16 \mathrm{SW} \\
15 \mathrm{ST}\end{array}$ & $1914 \mathrm{SW}$ & $\begin{array}{r}1162 \mathrm{~W} \\
17 \mathrm{ST} \\
2 \mathrm{SW}\end{array}$ & $1376 \mathrm{SW}$ & $\begin{array}{c}2154 \mathrm{SW} \\
21 \mathrm{~W}\end{array}$ & $1484 \mathrm{SW}$ & $2648 \mathrm{SW}$ & $1457 \mathrm{SW}$ \\
\hline
\end{tabular}

* Cells from a 24-48 h culture of $C$. albicans ATCC 26555 on Sabouraud-dextrose slope were suspended in double glass-distilled water and plated (500-1000 c.f.u. per plate) on the defined medium of Lee et al. (1975), containing zinc and arginine (LAZ medium; see Methods). Plates were incubated at $28^{\circ} \mathrm{C}$ for $5-7 \mathrm{~d}$ prior to assessment of colony phenotype.

+ Cells from the respective primary, secondary and tertiary colonial morphologies were resuspended in sterile glass-distilled water, counted and plated (approx. 200 c.f.u. per plate) on the indicated growth media. Plates were incubated at $28^{\circ} \mathrm{C}$ for $5-7 \mathrm{~d}$. 


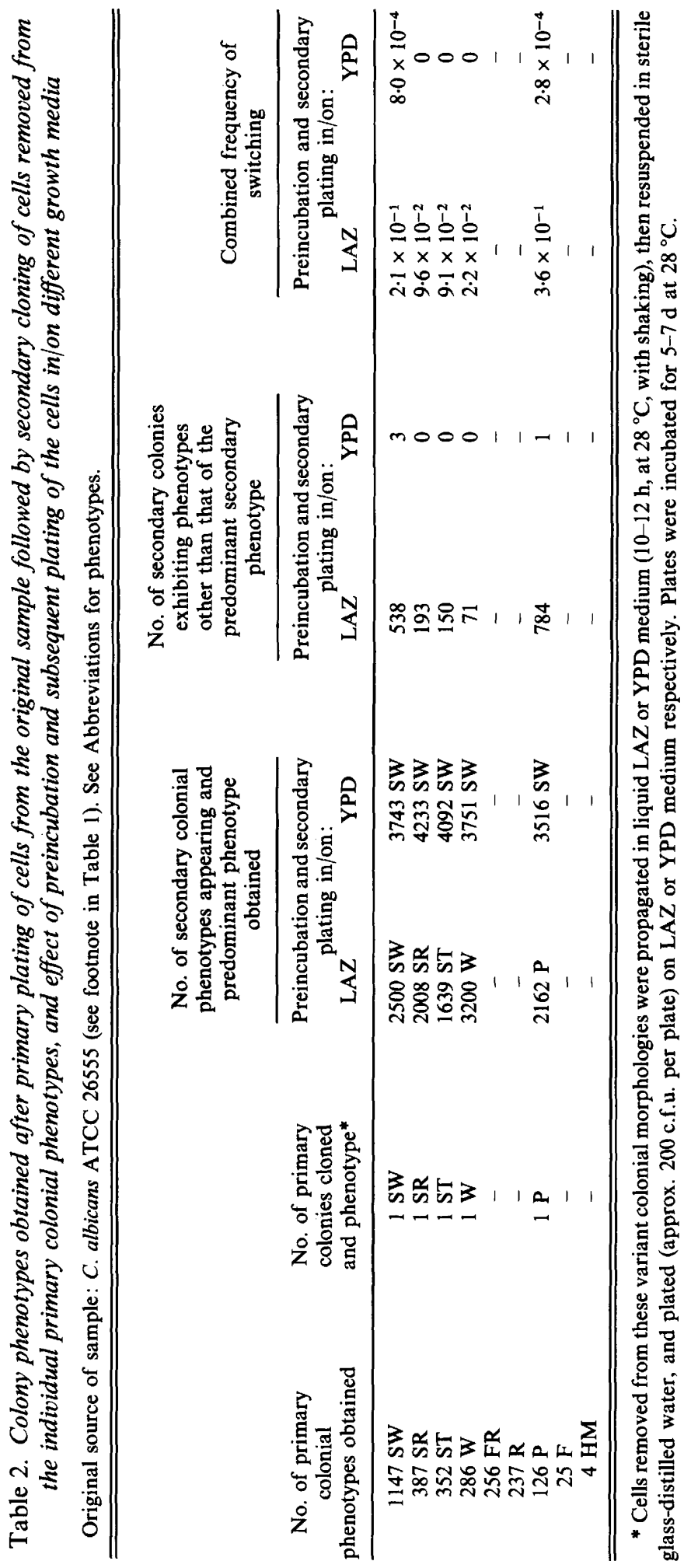





Fig. 1. Variant colonial phenotypes of $C$. albicans ATCC 26555. Each panel contains colonies representative of the different phenotypes. Clonal colonies were grown on LAZ agar at $28^{\circ} \mathrm{C}$ for $6 \mathrm{~d}$ (see Tables 1 and 2$)$. (a) Wrinkled (W); (b) smooth-white (SW); (c) star (ST); (d) smooth-white-petite (P), and heavy-myceliated (HM); $(e)$ ring (R); $(f)$ fuzzy (F) with a confluent SW colony; $(g)$ flat-ring (FR); $(h)$ stippled-ring (SR). Panel $(i)$ shows the simultaneous appearance of different colonial morphologies similar to those shown in the other panels of the figure.

term 'flat-ring' to describe it], $237(8.4 \%)$ were ring, 126 $(4.5 \%)$ were smooth-white-petite (P; Fig. 1 d), $25(0 \cdot 9 \%)$ were fuzzy (F; Fig. $1 f)$, and $4(0 \cdot 15 \%)$ were heavymyceliated (HM; Fig. 1d). W colonies (Fig. $1 a$ ) revealed an irregularly-shaped thick rim with deep wrinkling throughout their entire surface. SW colonies (Fig. $1 b$ ) exhibited an unmottled creamy-white surface. Colonies with the ST morphology (Fig. 1c) possessed a slightly thickened perimeter, which surrounded a star with a variable number of arms projecting peripherally and were equidistant from one another. $\mathrm{P}$ colonies (Fig. $1 d$ ) were similar to SW colonies in appearance, but significantly smaller in size. HM colonies (Fig. $1 d$ ) were small and irregular in shape, with aerial mycelia emanating from the entire colony surface. Colonies with the $\mathbf{R}$ appearance (Fig. 1e) exhibited a very thick outer edge, encompassing up to one-half of their radius and their centres were slightly mottled in texture. F colonies (Fig. 
1f) exhibited a thickened, irregular rim and a thin interior, with aerial mycelia emanating from the entire colony surface. Colonies with the SR appearance (Fig. $1 h$ ) were characterized by a peripheral thick rim around a depressed and mottled central area. Finally, FR colonies (Fig. $1 \mathrm{~g}$ ) were similar to SR colonies but were flatter, with a slightly mottled centre delimited by a thick peripheral rim.

\section{Effect of growth medium on the switching capabilities of the isolated phenotypes}

To test whether the variant colony morphologies isolated after the initial plating were heritable, cells removed from primary SW and $W$ clones were resuspended in sterile distilled water and plated as clones on LAZ medium. As shown in Table 1, the parental SW and $\mathrm{W}$ phenotypes reappeared en masse in the secondary progeny along with a low percentage of switch phenotypes, detected at frequencies of $7.4 \times 10^{-3}$ to $9.5 \times 10^{-3}$. However, an extremely high level of spontaneous switching was observed when cells from SW, W, ST, SR, and $P$ clones (Table 2 ) were individually grown in liquid LAZ medium and then plated as clones on LAZ agar. This indicates, in agreement with previous reports (Anderson \& Soll, 1987; Slutsky et al., 1985, 1987; Soll et al., 1987), that the limited zinc content of LAZ medium not only assures but apparently increases expression of the colonial variant phenotypes. Of 2500 secondary mature colonies that appeared after plating of cells from a SW colony, $538(21.5 \%)$ exhibited morphologies other than that of the original phenotype, which represented a combined frequency of switching of $2 \cdot 1 \times 10^{-1}$ (Table 2 ). The highest combined frequency of switching $\left(3.6 \times 10^{-1}\right)$ was observed in colonies cloned from a $\mathbf{P}$ colony; in this case, from 2162 colonies examined, 784 $(36.2 \%)$ had a morphological appearance distinct from that of the parental colony phenotype (Table 2). Slightly lower values of combined switching frequencies (from $2.2 \times 10^{-2}$ to $9.6 \times 10^{-2}$ ) were observed after plating of cells from W, ST or SR clones (Table 2).

In contrast, direct plating on YPD agar of cells removed from secondary SW or W colonies that appeared on LAZ (Table 1) or, alternatively, preincubation of cells removed from primary SW, W, ST, SR and P clonal colonies (Table 2) in YPD broth followed by plating of these cells on the same medium, led to the recovery of SW colonies in all cases (Table 1 and 2), with two exceptions. In the case of the colonies cloned from a primary SW colonial phenotype (3746), all but two SR colonies and one SW colony with a wrinkled sector (combined frequency of switching, $8.0 \times 10^{-4}$ ) exhibited the parental SW phenotype (Table 2). Among the 3517 secondary colonies cloned in YPD medium from a primary $\mathbf{P}$ colony all but one $\mathbf{P}$ colony were $\mathrm{SW}$, which represented a switching frequency of $2.8 \times 10^{-4}$ (Table 2). The evident loss of colonial phenotypic switching observed in YPD medium (see Tables 1 and 2) may be possibly caused by the high zinc content in this undefined medium (which contains roughly 500-fold more zinc than LAZ medium as determined by atomic absorption spectrometry), since excess of zinc apparently suppresses the appearance of switch phenotypes in other C. albicans strains (Anderson \& Soll, 1987; Slutsky et al., 1985, 1987; Soll et al., 1987). However, the parental variant phenotypes (SW, W or ST) reappeared after plating on LAZ medium of cells from SW colonies derived from SW, W or ST colonies, respectively (Tables 1 and 2).

\section{Selective effect of incubation temperature and growth medium composition on wrinkled and star cells}

Since the stock cultures of the strain ATCC 26555 used to obtain primary phenotypes had been routinely stored at $4{ }^{\circ} \mathrm{C}$ for prolonged periods, and because all incubations for initial analysis of switching were carried out at $28^{\circ} \mathrm{C}$, we considered it of interest to assess the effects of growth temperature $\left(37^{\circ} \mathrm{C}\right.$ vs $28^{\circ} \mathrm{C}$, taking into account the opportunistic pathogenic character of $C$. albicans) in combination with different culture media on the phenotypic switching.

To perform these experiments, cells from stabilized tertiary W and ST single clones grown on solid LAZ medium as described above (see Table 3 ), were removed and incubated for two consecutive rounds in liquid YPD medium at $28^{\circ} \mathrm{C}$ (Table 3; Fig. 2), and then plated on LAZ or YPD media. Duplicate sets of plates were incubated at either $28^{\circ} \mathrm{C}$ or $37^{\circ} \mathrm{C}$ for $5-7 \mathrm{~d}$. At $28^{\circ} \mathrm{C}$ on $\mathrm{LAZ}$ medium the quaternary colonies examined exhibited the morphological shape corresponding to that of the parental tertiary colonial variant from which the cells were plated as clones (Table 3), that is to say the ST (Fig. $2 a$ ) or W (Fig. $2 e$ ) phenotypes. However, at $37^{\circ} \mathrm{C}$ all colonies cloned on LAZ medium from either ST or W tertiary colonies were hyper-wrinkled (HW; Fig. $2 b, f$; Table 3). When cells were plated on YPD medium and incubated at $28^{\circ} \mathrm{C}$, the colony morphology observed was SW regardless of the original tertiary clonal phenotypes (ST or W) from which the cells were plated as clones (Fig. $2 c, g$ ). A SW phenotype was also obtained after plating of cells from a single ST colony on YPD medium at $37^{\circ} \mathrm{C}$ (Fig. 2d). However, when cells from a W colony were plated as clones under the same growth conditions, all quaternary colonies examined exhibited a new morphological appearance, which we designated as intermediate-smooth-white-wrinkled phenotype (ISWW; Fig. $2 h$; Table 3). As suggested by other authors (Dutton \& Penn, 


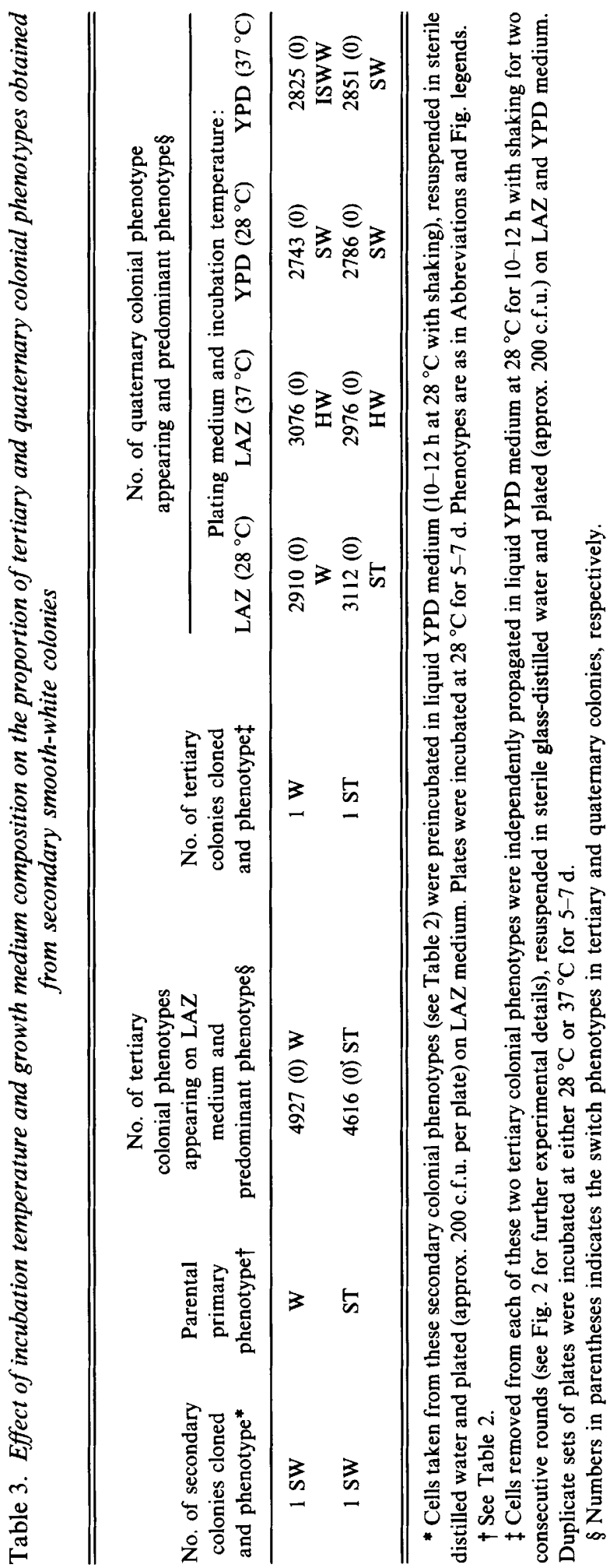



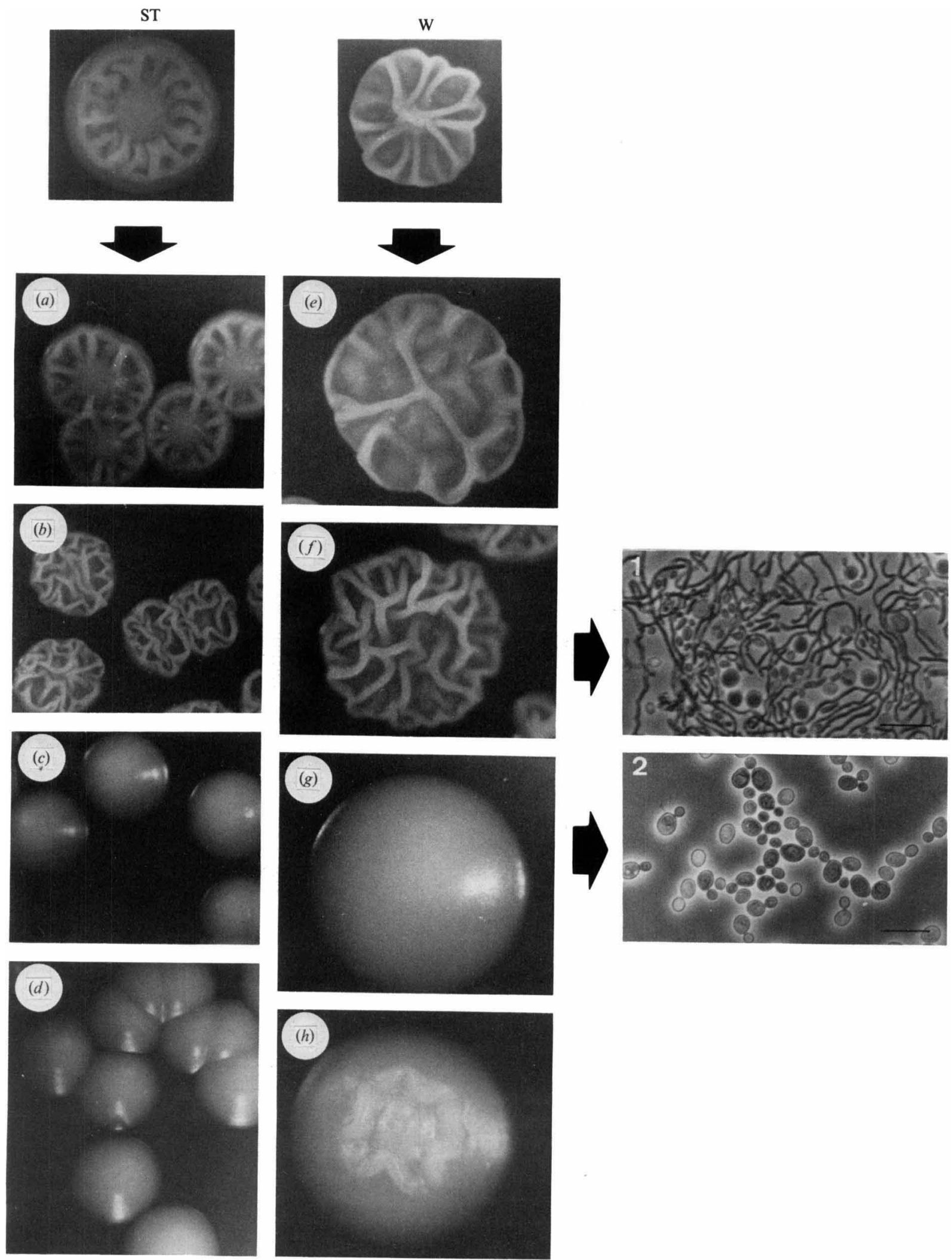
1989) the colony morphology appears to be determined by the relative proportions of mycelial or yeast forms, as the cells removed from SW colonies were exclusively in the budding form of growth (Fig. 2, panel 2), whereas W and HW colonies contained mostly mycelial cells (Fig. 2, panel 1). ST and ISWW colonies contained roughly equal amounts of budding cells and mycelial filaments.

\section{Characterization of wall mannoproteins isolated from different colony phenotypes}

Purified walls obtained from cell samples removed from ST (Fig. 2a), W (Fig. 2e), HW (Fig. 2b, f), SW (Fig. $2 c$, $d, g$ ), and ISWW (Fig. $2 h$ ) colonies, were digested with Zymolyase and the solubilized mannoprotein material separated by SDS-PAGE. Mannoproteins electrophoretically transferred to nitrocellulose paper by Western blotting, were detected with ConA, a polyclonal antiserum enriched in antibodies against wall components specific for the mycelial morphology (mPAb), or a monoclonal antiserum (mAb 4C12).

The mannoprotein nature of the molecules solubilized by the $\beta$-glucanase complex was revealed by $\operatorname{ConA}-$ peroxidase staining of the nitrocellulose blots (Fig. $3 a$ ). Different mannoproteins with molecular masses ranging from higher than $600 \mathrm{kDa}$ down to about $30 \mathrm{kDa}$ were visualized. Mannoproteins with apparent molecular masses $>200 \mathrm{kDa}$ were particularly abundant in enzymic digests of wall preparations from cells of SW (Fig. $3 a$, lanes 3, 4, 7), ST (Fig. 3a, lane 1) and ISWW (Fig. $3 a$, lane 8) colonies. Polydispersity of the high-molecularmass mannoproteins was high, especially in those lanes that were loaded with material released by Zymolyase from cells belonging to heavily myceliated colonial phenotypes (Fig. $3 a$, lane 6). This phenomenon may result from an increase in the glycosylation of some wall mannoprotein species.

A polyclonal antiserum generated against mannoprotein components of purified wall preparations from blastospores bearing germ tubes (mPAb; Casanova et al., 1989) was also tested on the enzymic digests by immunoblotting, and several of the high-molecular-mass mannoprotein species visualized by ConA (Fig. $3 a$ ) had antigenic determinants which were recognized by the mPAb preparation (Fig. $3 b$ ). Very large antigenic mannoproteins $(>500 \mathrm{kDa}$ ) were detected almost exclusively in the digests of wall preparations from cells of SW (Fig. $3 b$, lanes 3, 4, 7), ST (Fig. $3 b$, lane 1), and ISWW (Fig. $3 b$, lane 8 ) colonies. This result agrees with that for ConA (above).

Finally, a monoclonal antibody (mAb $4 \mathrm{C} 12$ ) raised against a mycelium-specific wall mannoprotein band with an apparent molecular mass of $260 \mathrm{kDa}$ (Casanova et al., 1989), reacted with various mannoprotein bands with apparent molecular masses of $>200 \mathrm{kDa}$ (Fig. $3 c$ ). Such species were detected in the wall digests of cells from ST (Fig. 3c, lane 1), W (Fig. 3c, lane 5), HW (Fig. $3 c$, lanes 2,6) and ISWW (Fig. $3 c$, lane 8) colonies, which all contained, as stated above, variable proportions of mycelial growth forms. In contrast, mAb $4 \mathrm{Cl} 2$ did not react with the enzymically solubilized material from the walls of SW phenotype cells (Fig. $3 c$, lanes 3, 4, 7 ), which were exclusively in the budding form of growth, although these digests contained a great assortment of mannoprotein species, as revealed by ConAperoxidase staining (Fig. $3 a$, lanes 3, 4, 7).

\section{Discussion}

The spontaneous high frequency of switching in colony morphology on agar media reported in this study of $C$. albicans ATCC 26555 (a common laboratory strain) is similar to the switching system initially described by Slutsky et al. (1985) in strain 3153A of C. albicans.

Various genetic mechanisms have been invoked to explain the molecular basis of phenotypic transitions in C. albicans (Morrow et al., 1989; Pomés et al., 1987; Rustchenko-Bulgac et al., 1990; Scherer \& Stevens, 1988; Slutsky et al., 1985; Soll et al., 1987; Suzuki et al., 1989) Our results suggest that some environmental conditions (i.e. the growth medium and/or the incubation temperature) may differentially affect expression of a set of genes (which among other possibilities, may change the activity of enzymes that synthesize wall components) responsible for the manifestation of differ-

Fig. 2. Effect of temperature and growth medium on the expression of variant colony morphologies. From star (ST) or wrinkled (W) tertiary clonal colonies (see Table 3), cells were inoculated into liquid YPD medium and rotated on a gyratory incubator (250 r.p.m.) at $28^{\circ} \mathrm{C}$ for $10-12 \mathrm{~h}$. Cells from these cultures were transferred to fresh liquid YPD medium at an initial concentration of $5 \times 10^{4}$ spheres or cells per $\mathrm{ml}^{-1}$, and incubated again as described above for an additional 10-12 h. Cells from these cultures were suspended in water and plated on solid LAZ medium $(a, b, e, f)$, and YPD medium $(c, d, g, h)$. Plates were incubated at $28^{\circ} \mathrm{C}(a, e, c, g)$, and at $37^{\circ} \mathrm{C}(b, f, d$, $h$ ). Samples removed from the surface of colonies exhibiting the star $(a)$, wrinkled $(e)$, hyper-wrinkled $(\mathrm{HW} ; b, f)$, or intermediate smooth-white-wrinkled (ISWW; $h$ ) morphologies contained variable amounts of budding cells and mycelial filaments (panel 1 ; see text), whereas cells removed from smooth-white colonies $(c, d, g)$ were exclusively in the budding form of growth (panel 2). Panels 1 and 2 are phase-contrast observations. Bar, $12.5 \mu \mathrm{m}$. 

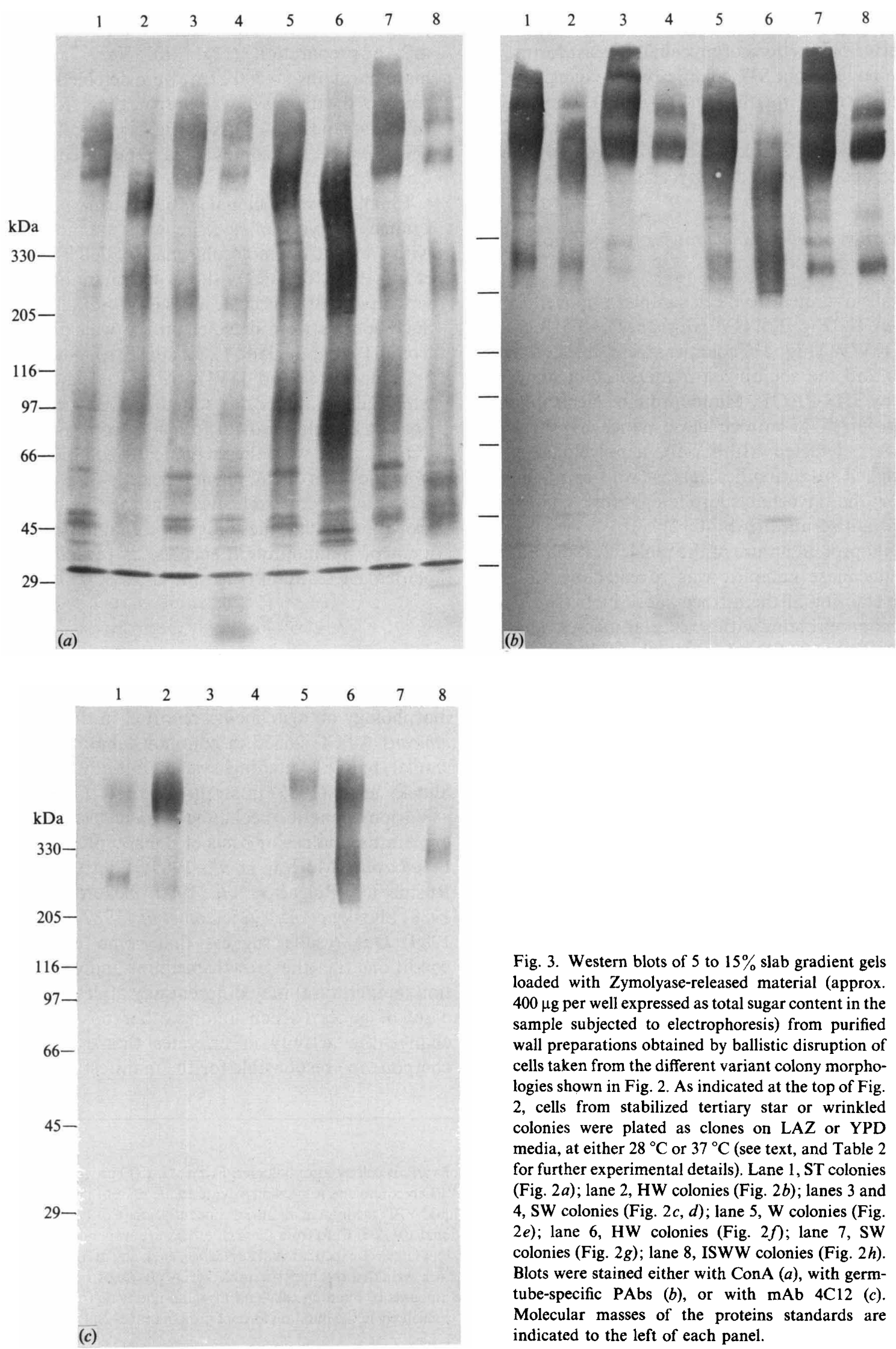

Fig. 3. Western blots of 5 to $15 \%$ slab gradient gels loaded with Zymolyase-released material (approx. $400 \mu \mathrm{g}$ per well expressed as total sugar content in the sample subjected to electrophoresis) from purified wall preparations obtained by ballistic disruption of cells taken from the different variant colony morphologies shown in Fig. 2. As indicated at the top of Fig. 2 , cells from stabilized tertiary star or wrinkled colonies were plated as clones on LAZ or YPD media, at either $28^{\circ} \mathrm{C}$ or $37^{\circ} \mathrm{C}$ (see text, and Table 2 for further experimental details). Lane 1, ST colonies (Fig. 2a); lane 2, HW colonies (Fig. 2b); lanes 3 and 4, SW colonies (Fig. $2 c, d$ ); lane 5, W colonies (Fig. $2 e$ ); lane 6, HW colonies (Fig. 2f); lane 7, SW colonies (Fig. $2 g$ ); lane 8, ISWW colonies (Fig. 2h). Blots were stained either with ConA $(a)$, with germtube-specific PAbs (b), or with mAb $4 \mathrm{Cl} 2$ (c). Molecular masses of the proteins standards are indicated to the left of each panel. 
ent colonial phenotypes. These results agree with previously published reports indicating that certain extracellular conditions can affect switching in the white-opaque transition of C. albicans (Rikkerink et al., 1988; Slutsky et al., 1987).

The appearance of two new colonial variants, the hyper-wrinkled (HW) and intermediate-smooth-whitewrinkled (ISWW) phenotypes, when cells were plated respectively on LAZ and YPD agar and incubated at $37^{\circ} \mathrm{C}$, was interesting. HW colonies had mostly mycelial filaments, and ISWW colonies contained roughly equal amounts of budding cells and hyphae, although the latter were observed on YPD medium (Table 3), which suppressed phenotype expression and produced only SW colonies that contained only yeast cells. As $37^{\circ} \mathrm{C}$ is the natural temperature of the human body, and mycelial filaments are thought to be more invasive than budding cells, the appearance of these seemingly temperaturedependent switch phenotypes (HW and ISWW) may relate to the in vivo role of switching in pathogenesis.

On the other hand it has been reported that in the white-opaque high-frequency transition system (Slutsky et al., 1987), the switch between white and opaque phenotypes is accompanied by changes in the adhesion characteristics and surface properties of cells (Kennedy et al., 1988), and by changes in the antigenic composition of the cell surface (Anderson \& Soll, 1987; Anderson et al., 1989, 1990). Attempts to determine the surface components of $C$. albicans involved in adherence and antigenicity have revealed that cell wall mannoproteins fulfil this role (Casanova et al., 1989; Chaffin et al., 1988; Douglas, 1987; Sundstrom et al., 1988). A novel feature of this work is the characterization of antigenic mannoproteins released by Zymolyase from the cell walls of different phenotypes.

We have detected a complex mannoprotein composition in the walls of cells belonging to the ST, W, HW, SW and ISWW quaternary clones (Fig. $2 a-h$ ). Some of these mannoproteins exhibited reactivity towards the mPAb preparation, and differences in the pattern of antigenic mannoproteins were observed depending on the phenotype considered. However, it has to be stressed that the mPAb, which was prepared by repeated absorption of an antiserum raised against mycelial cell walls with blastoconidia, still contained antibodies against yeast-specific wall components (Casanova et al., 1989). Hence, the differences in the pattern of antigens revealed by the mPAb could be due to the expression of yeast- and mycelium-specific cell-wall mannoproteins, whose relative proportions in the Zymolyase digests may vary depending on the percentage of yeasts and mycelial filaments present in each colonial phenotype (see above). Further evidence reinforcing this possibility came from experiments performed with the monoclonal antibody
$\mathrm{mAb} 4 \mathrm{C} 12$. This antibody was initially raised against a mannoprotein band with an apparent molecular mass of $260 \mathrm{kDa}$, which was specific for the mycelial-phase walls (Casanova et al., 1989). However, further experiments in our laboratory have revealed that $\mathrm{mAb} 4 \mathrm{Cl} 2$ also recognizes a $180 \mathrm{kDa} O$-glycosylated mannoprotein (p180) which is secreted by regenerating protoplasts obtained from mycelial cells, and which appears to be the precursor of the $260 \mathrm{kDa}$ mycelium-specific band (Elorza et al., 1989). As expected, the monoclonal antibody reacted only with mannoprotein antigens in the wall digests from cells of the ST, W, HW, or ISWW clones, which all contained cells in the hyphal growth form.

However, it is also possible that changes in the molecular structure of the wall mannoproteins may affect, directly or indirectly (Goochee \& Monica, 1990), the way these mannoproteins are bound to other wall components, which may occur as a consequence of the expression of a particular phenotype. This possibility arises from the observation that $\mathrm{mAb} 4 \mathrm{C} 12$ reacted with mannoprotein bands whose relative proportions in the quaternary ST, W, HW, or ISWW colony digests (equal amounts of the different samples expressed as total sugar content were subjected to electrophoresis), as well as their degree of polydispersity, appear to vary depending on the colonial switch phenotype considered. Given that $\mathrm{mAb} 4 \mathrm{C} 12$ is apparently directed against an epitope in the peptide moiety of $\mathrm{p} 180$, the different mannoprotein bands detected by the monoclonal antibody may reflect variations in the glycosylation levels of $\mathrm{p} 180$, or, more likely, in the way this molecule interacts with other wall components, which would result in the solubilization by Zymolyase of supramacromolecular complexes with different mobilities. There is evidence for the formation of covalent bonds between chitin and glucans (Surarit $e t$ $a l ., 1988)$, and the p180 mannoprotein and other wall proteins and glucans (Elorza et al., 1989) or chitin (unpublished observations). If these changes occur concomitantly with the expression of specific colonial phenotypes, they may confer new surface properties upon the cells expressing such phenotypes, which could in turn modulate the opportunistically pathogenic character of C. albicans.

This work was partially supported by a grant (PB87-0606) of the Dirección General de Investigación Científica y Técnica (Spain). M.L.G. was the recipient of a predoctoral grant from the Fondo de Investigaciones Sanitarias (Spain). J.L.L.R. is a predoctoral fellow from the Plan de Formación del Personal Ivestigador, Ministerio de Educación y Ciencia (Spain). We are indebted to Lucas del Castillo for helpful discussions, and to Jordi Mañes for kindly evaluating zinc concentrations in the culture media by atomic absorption spectrometry. 


\section{References}

Anderson, J. M. \& Soll, D. R. (1987). Unique phenotype of opaque cells in the white-opaque transition of Candida albicans. Journal of Bacteriology 169, 5579-5588.

Anderson, J., Cundiff, L., Schnars, B., Gao, M., Mackenzie, J. \& SolL, D. R. (1989). Hypha formation in the white-opaque transition of Candida albicans. Infection and Immunity 57, 458-467.

ANDERSON, J., Mihalix, R. \& Soll, D. R. (1990). Ultrastructure and antigenicity of the unique cell wall pimple of the Candida opaque phenotype. Journal of Bacteriology 172, 224-235.

BeDELl, G. \& SolL, D. R. (1979). The effects of low concentrations of zinc on the growth and dimorphism of Candida albicans: evidence for zinc-resistant and zinc-sensitive pathways for mycelium formation. Infection and Immunity 26, 348-354.

Bodey, G. P. \& Fainstein, V. (editors) (1985). Candidiasis. New York: Raven Press.

BURNETTE, W. N. (1981). 'Western blotting': electrophoretic transfer of proteins from sodium dodecyl sulfate-polyacrylamide gels to unmodified nitrocellulose and radiographic detection with antibody and radioiodinated protein A. Analytical Biochemistry 112, 195-203.

Casanova, M., Gil, M. L., Cardeñoso, L., Martinez, J. P. \& SENTANDREU, R. (1989). Identification of wall-specific antigens synthesized during germ tube formation by Candida albicans. Infection and Immunity 57, 262-271.

Chaffin, W. L., Skudlarek, J. \& Morrow, K. J. (1988). Variable expression of a surface determinant during proliferation of Candida albicans. Infection and Immunity 56, 302-309.

Chandler, F. W. (1985). Pathology of the mycoses in patients with the acquired immunodeficiency syndrome (AIDS). Current Topics in Medical Mycology 1, 1-23.

Douglas, L. J. (1987). Adhesion to surfaces. In The Yeasts, 2nd edn., pp. 239-280. Edited by A. H. Rose \& J. S. Harrison. London: Academic Press.

Dubois, M., Gilles, K. A., Hamilton, J. K., Rebers, P. A. \& SMith, F. (1956). Colorimetric method for determination of sugars and related substances. Analytical Chemistry 28, 350-356.

Dutton, S. \& PenN, C. W. (1989). Biological attributes of colony-type variants of Candida albicans. Journal of General Microbiology 135, 3363-3372.

elorza, M. V., Mormeneo, S., Garcia De la Cruz, F., Gimeno, C. \& SENTANDREU, R. (1989). Evidence for the formation of covalent bonds between macromolecules in the domain of the wall of Candida albicans mycelial cells. Biochemical and Biophysical Research Communications 162, 1118-1125.

GOOCHEE, C. F. \& MoNiCA, F. (1990). Environmental effects on protein glycosylation. Biotechnology 8, 421-427.

HAWKES, R. (1982). Identification of concanavalin-A-binding proteins after sodium dodecyl sulfate-gel electrophoresis and protein blotting. Analytical Biochemistry 123, 143-146.

Kennedy, M. J., Rogers, A. L., Hanselmen, L. R., Soll, D. R. \& YANCEY, R. J., JR (1988). Variation in adhesion and cell surface hydrophobicity in Candida albicans white and opaque phenotypes. Mycopathologia 102, 149-156.

LAEMMLI, U. K. (1970). Cleavage of structural proteins during the assembly of the head of bacteriophage T4. Nature, London 227, 680685 .

LEe, K. L., BuCKLey, H. R. \& CAMPBell, C. C. (1975). An amino acid liquid synthetic medium for the development of mycelial and yeast forms of Candida albicans. Sabouraudia 13, 148-153.

MiLLETTE, C. F. \& SCOTT, B. K. (1984). Identification of spermatogenic cell plasma membrane glycoproteins by two dimensional electrophoresis and lectin blotting. Journal of Cell Science 65, 233-248.
Morrow, B., ANDerson, J., Wilson, J. \& Soll, D. R. (1989). Bidirectional stimulation of the white-opaque transition of Candida albicans by ultraviolet irradiation. Journal of General Microbiology 135, 1201-1208.

ODds, F. C. (1987). Candida infections: an overview. Critical Reviews in Microbiology 15, 1-5.

ODDS, F. C. (editor). (1988). Candida and Candidosis. London: Baillière-Tindall.

Pomes, R., Gil, C., Cabetas, M. D. \& Nombela, C. (1987). Variability of colonial morphology in benomyl-induced morphological mutants from Candida albicans. FEMS Microbiology Letters 48, 255-259.

Poulain, D., Hopwood, V. \& Vernes, A. (1985). Antigenic variability of Candida albicans. Critical Reviews in Microbiology 12, 223-270.

Rikkerink, E. H. A., Magee, B. B. \& Magee, P. T. (1988). Opaquewhite phenotype transition: a programmed morphological transition in Candida albicans. Journal of Bacteriology 170, 895-899.

Rogers, T. J. \& Balish, E. (1980). Immunity to Candida albicans. Microbiological Reviews 44, 660-682.

Rustchenko-Bulgac, E. P., Sherman, F. \& Hicks, J. B. (1990). Chromosomal rearrangements associated with morphological mutants provide a means for genetic variation of Candida albicans. Journal of Bacteriology 172, 1276-1283.

SCherer, S. \& Stevens, D. A. (1988). A Candida albicans dispersed, repeated gene family and its epidemiologic applications. Proceedings of the National Academy of Sciences of the United States of America 85, $1452-1456$.

SluTSKY, B., BufFo, J. \& Soll, D. R. (1985). High-frequency 'switching' of colony morphology in Candida albicans. Science $\mathbf{2 3 0}$, 666-669.

Slutsky, B., Staebell, M., Anderson, J., Risen, L., Pfaller, M. \& Soll, D. R. (1987). 'White-Opaque transition': a second highfrequency switching system in Candida albicans. Journal of Bacteriology 169, 189-197.

Soll, D. R., Langtimm, C. J., McDowell, J., Hicks, J. \& Galask, R. (1987). High-frequency switching in Candida strains isolated from vaginitis patients. Journal of Clinical Microbiology 25, 1611-1622.

Soll, D. R., Staebell, M., Langtimm, C., Pfaller, M., Hicks, J. \& RAO, T. V. G. (1988). Multiple Candida strains in the course of a single systemic infection. Journal of Clinical Microbiology 26, 14481459.

Soll, D. R., Galask, R., Isley, S., Rao, T. V. G., Stone, D., Hicks, J., SCHMID, J., MAC, K. \& HANNA, C. (1989). Switching of Candida albicans during successive episodes of recurrent vaginitis. Journal of Clinical Microbiology 27, 681-690.

Sundstrom, P. M., Tam, M. R., Nichols, E. J. \& KenNY, G. E. (1988). Antigenic differences in the surface mannoproteins of Candida albicans as revealed by monoclonal antibodies. Infection and Immunity 56, 601-606.

Surarit, R., Gopal, P. K. \& ShePherd, M. G. (1988). Evidence for a glycosidic linkage between chitin and glucan in the cell wall of Candida albicans. Journal of General Microbiology 134, 1723-1730.

Suzuki, T., Kobayashi, I., Kanbe, T. \& Tanaka, K. (1989). Highfrequency variation of colony morphology and chromosome reorganization in the pathogenic yeast Candida albicans. Journal of General Microbiology 135, 425-434.

TAPPER-Jones, L. M., Aldred, M. J., Walker, D. M. \& HaYes, T. M. (1981). Candida infections and populations of Candida albicans in mouths of diabetics. Journal of Clinical Pathology 34, 706-711.

Towbin, H., Staehelin, T. \& GoRdon, J. (1979). Electrophoretic transfer of proteins from polyacrylamide gels to nitrocellulose sheets: procedure and some applications. Proceedings of the National Academy of Sciences of the United States of America 76, 4350-4354. 